Original Research Paper

\title{
Mapping of Flood Risk Zones in Ala River Basin Akure, Nigeria
}

\author{
${ }^{1}$ Olajire Olabanji Olatona, ${ }^{2}$ O.A. Obiora-Okeke and ${ }^{2}$ J.R. Adewumi \\ ${ }^{I}$ Department of GIS and Remote Sensing, (ARCSSTEE Program), Federal Univerity of Technology, Akure, Nigeria \\ ${ }^{2}$ Department of Civil Engineering, Federal University of Technology Akure, Nigeria
}

\author{
Article history \\ Received: 12-11-2016 \\ Revised: $30-11-2016$ \\ Accepted: 10-05-2017 \\ Corresponding Author: \\ Olajire Olabanji Olatona \\ Department of GIS and Remote \\ Sensing, (ARCSSTEE \\ Program), Federal Univerity of \\ Technology, Akure, Nigeria \\ Email: hollycesra@gmail.com
}

\begin{abstract}
Floods are water induced disasters that lead to temporary inundation of dry land and cause serious damages in the affected location such as loss of lives and properties and destruction of infrastructures. Nigeria has experienced a lot of flood incidences and the impact of flood has also increased due to population growth coupled with uncontrolled developmental practices. The result of this is pressure and congestion in urban land areas. This in turn forces a considerable number of people to settle in unsafe areas with inherent risk to flood which is the case in Ala river basin, Akure, Ondo state. The aim of this research study to make an assessment of flood risk vulnerability in Ala river basin area. Multicriteria Evaluation methods were used to analyse flood vulnerable areas. The causative factors of flood within the basin taken into consideration includes slope, distance to drainage, drainage density, soil type and land use. Geographical information system was integrated with Fuzzy Logic to classify the various causative criteria. Fuzzy overlay was used to generate the flood risk map in Ala river basin identifying low, medium and high flood risk zones which would be made available to policy and decision makers as a decision support system in tackling flood.
\end{abstract}

Keywords: GIS, Fuzzy Logic, Flooding, Disaster Management, Multicriteria Analysis

\section{Introduction}

Flood is a natural environmental disaster which could be aggravated by man's unguided development. Floods cause damage to houses, industries, public utilities, agricultural land and crops resulting in huge economic loses, apart from loss of lives. Since flood is one of the environmental degradation problems which endanger both life and property, it becomes vital to know its extents and evolution. Though it is not possible to control flood disaster totally, by adopting suitable structural measures, flood damages can be minimized (Awosika and Folorunsho, 2000).

Floods are major disasters affecting many countries of the world annually, especially in most flood plain areas. Floods do not only damage properties and endanger the lives of human and animals but also produce other secondary effects like outbreak of diseases such as cholera and malaria as well. Flooding is commonly caused by heavy downpours of rains on flat ground, reservoir failure, volcano, melting of snow and or glaciers etc. Flood risk is not just based on history; but on a number of factors: Rainfall, river flow and tidal- surge data, topography, flood control measures and changes due to construction of building and development on flood plain areas (Suleiman et al., 2014).

Urban floods result from blocked or inadequate storm sewers and are due to increased urbanization (Ajin et al., 2013). Urban areas have high risk of flash flooding due to the presence of large impervious areas and sometimes inefficient drainage system (Chen et al., 2009; Huong and Pathirana, 2013; Sowmya et al., 2015). Several additional phenomena commonly contribute to urban flooding, such as limited conveyance capacity of urban channels and rivers, as well as drains and sewers and infiltration-inflow and decades of urban development without upgrading of the drainage infrastructure (Pedersen et al., 2012). The rapid growth often results in a poorly planned urbanization making urban populations increasingly vulnerable to floods.

Floods occur when the soil, stream channels and manmade reservoirs cannot absorb or contain all the water. A flood that occurs suddenly, with little or no prior signs, is called a flash flood and is due to intense rainfall over a relatively small area, it is inevitable, 
resulting from the natural rainfall-runoff process. It is a natural phenomenon and its magnitude is periodic. The periodicity of floods implies that every year some area surrounding the river (on both sides) is flooded. Every other period, (two, five, ten, fifty, one hundred and even a thousand years) is associated with increasing areas around the river which gets inundated.

Flood risk management can be roughly divided into two parts (Schanze 2006): Flood risk analysis and assessment on the one hand and risk mitigation on the other. Broadly speaking, the purpose of flood risk assessment is to establish where risk is unacceptably high, i.e., where mitigation actions would be necessary. Risk mitigation means to propose, evaluate and select measures to alleviate risks in these areas (Scheuer and Meyer, 2007).

One way to mitigate the effects of flood is to ensure that all areas that are vulnerable are identified and adequate precautionary measures taken to ensure adequate preparedness, effective response, quick recovery and effective prevention. Before these could be done, information is required on important indices of flood risk identification which are slope, distance to drainage, drainage density, Soil and landuse as applied in this research study. To get information on most of these and identify areas that are vulnerable to floods, reliable techniques of collecting and analyzing geospatial information are required. In this regard, an integrated approach of the knowledge of remote sensing and GIS can be used to investigate and map out areas that are less or more vulnerable to flooding (Suleiman et al., 2014).

\section{Statement of Problem}

Flooding along the Ala river in Akure metropolis is an annual occurrence. The unsafe condition of lives and properties along the river has over the years become an issue of serious concern to individuals, local, state and federal government. Properties worth billions of Naira are damaged yearly. Rainy season as usual is worse for the people living close to Ala river in Akure as residential buildings and business premises are submerged making life unbearable for the residents of these areas and patrons of business located there (http://seunaadebowale.blogspot.com.ng/2011/04/akuresecological-problems-and_26.html). GIS is a viable tool in flood risk assessment.

\section{Justification of Study}

The extent of flood hazard damages recorded in Ala River basin area has not been properly mapped as a result of inadequate preparations and lack of political will to fully investigate damages resulting from flood hazard. Providing basic information on flood dynamics, geospatial pattern and socio-economic and environmental impacts have remained sketchy on local communities like Ala River basin area. The goal of this study, therefore, is to assess flood risk and vulnerability with emphasis on Ala River basin in Akure Metropolis Ondo State, Nigeria.

\section{AIM and Objectives}

The aim of this research study to make an assessment of flood risk vulnerability in Ala river basin area.

The objectives are:

- To identify criteria that causes flooding in Ala river basin Area

- To classify each criteria according to their impact in causing flood

- To generate a flood risk map showing low, medium and high vulnerable areas

\section{Study Area}

Ala river basin lies within the Akure metropolis. Ala river basin extent is between $5^{\circ} 9^{\prime} \mathrm{E}, 7^{\circ} 17^{\prime} \mathrm{N}$ and $5^{\circ} 17^{\prime}$ E, $7^{\circ} 16^{\prime} \mathrm{N}$. Ala river is located in Akure South Local government. According to the Koppen classification scheme, the area lies within the AF climate type characterized by short dry season with precipitation not less than $60 \mathrm{~mm}$ at its driest. Geomorphologicaly, the study area falls within unevenly topographic landscapes characterized by features like spurs, saddles, valleys and river channels among several landforms. Geologically, the region forms part of the basement complex of the southwestern part of Nigeria (Rahaman, 1998; Jones and Hockey, 1964; Cooray, 1970). Major rock types around the area are Chanockite, Migmatite gneiss, Quartzite and Biotite gneiss. These Precambrian rocks have however, been subjected to tectonic activities and disturbed in various ways resulting in fracturing, jointing, cracking among others (Rahaman, 1988; Oyawoye, 1970). Figure 1 shows map of the study area.

\section{Data and Methodology}

Digital Elevation Model dataset containing elevation for Ala river area was acquired. The imagery acquired is the Shuttle Radar Topography Mission (SRTM). The imagery was used to generate the slope for the area using surface analysis tool in ArcGIS. The imagery was also used to generate the drainage network for the area using the hydrology tool in ArcGIS.

The soil data was acquired from the Harmonised World Soil Database. The image was saved in a format that is compatible with ArcGIS for further processing. The data was then digitised and convert to a raster file.

Google earth imagery for Ala river basin was acquired. The image was used to produce the landuse map for the basin area. The image was georeferenced using spatial references acquired from google earth. Supervised classification was then performed on the georeferenced image using maximum likelihood method. The final result was the classified land use map. 


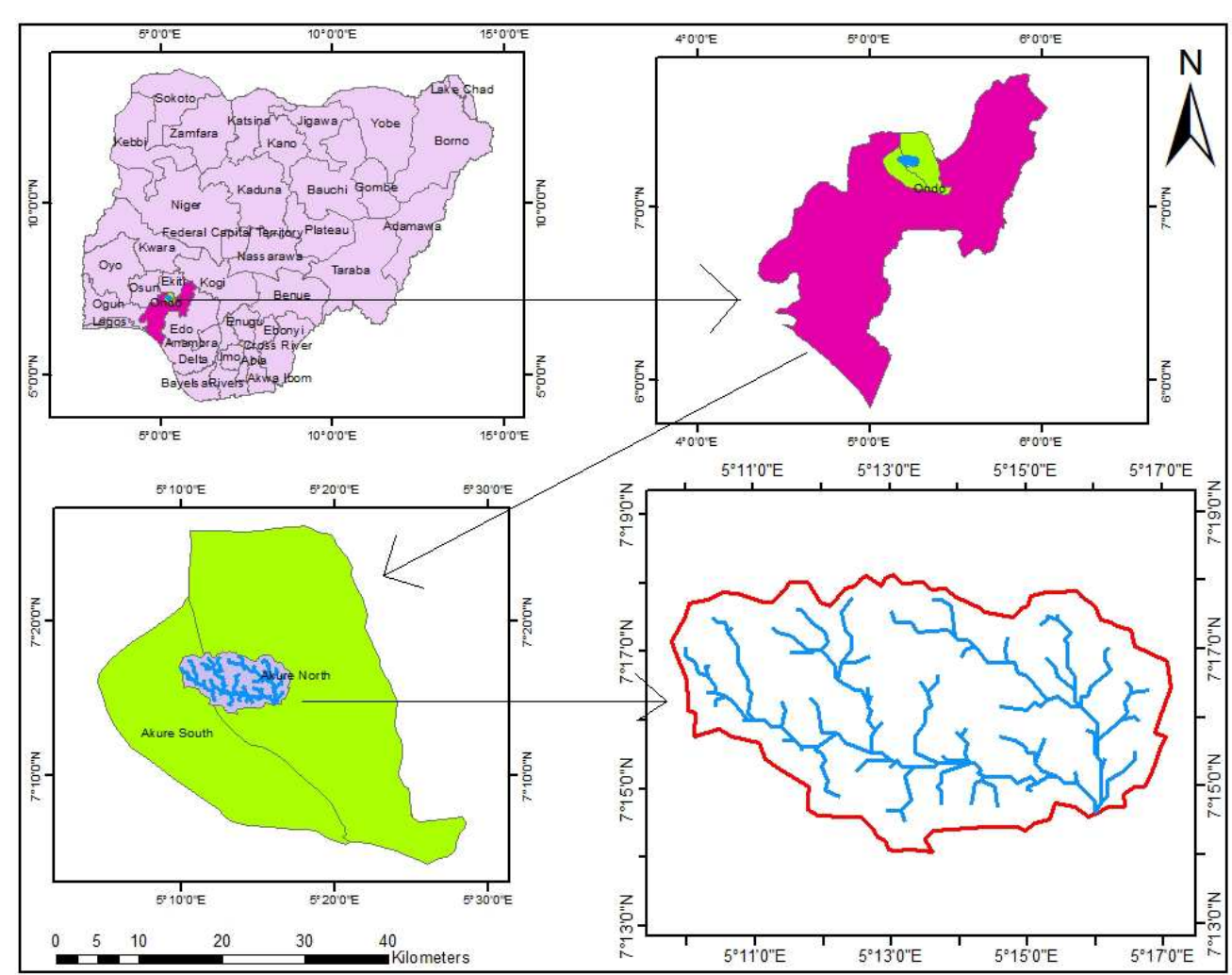

Fig. 1: Study area map showing Ala river location

Spatial analyst tool was used to generate the drainage density map from the existing drainage map. This was further reclassified for the analysis.

The maps of the various criteria were then assigned fuzzy membership classes using the python command prompt in ArcGIS. The membership code classified the criteria based on their level of influence in causing flood.

The fuzzy members were then overlayed using the codes in the command prompt of ArcGIS. The final output map was the flood risk map which was classified into low, medium and high vulnerability.

\section{Analysis and Discussion}

\section{SLOPE}

Slope map was generated from Digital Elevation Model (DEM) using the Shuttle Radar Topography Mission (SRTM) imagery. The slope distribution for the study area ranges from $0-22.54^{\circ}$. Areas with slope degree ranging from $0-5$ are flat or almost flat, water from higher slope areas would tend to gather that this low slopy areas. Figure 2 shows the slope map.

\section{Distance to Drainage}

The drainage pattern was generated from the Shuttle Radar Topography Mission (SRTM) Imagery using hydrology analysis tool in ArcGIS. Various distances to the drainage were created to signify susceptibility to flood. The distances were classified into four. The first distance was $30 \mathrm{~m}$ to indicate areas along the drainage that are highly susceptible to flood. The $30 \mathrm{~m}$ set back is in line with the Town and Regional planning (Building Plan) Regulation, 1986. The regulation states that residential buildings must be at least $30 \mathrm{~m}$ away from major water channels; this is to prevent exposure to flooding and to protect watersheds. The second distance to river was set at $70 \mathrm{~m}$ in case of eventualities where the flood extent exceeds the $30 \mathrm{~m}$ distance. The third distance to river was set at $150 \mathrm{~m}$ to identify areas that are less vulnerable to flood. The fourth distance was set at greater than 150 $\mathrm{m}$ to indicate areas that might not be affected by flood at all. Figure 3 shows the drainge pattern and Fig. 4 shows the map of distance to drainage in the study area.

\section{Drainage Density}

The drainage density for the study area was generated from the drainage pattern in the study area. The drainage density was classified into three; low, medium and high density. High drainage density indicate areas with high vulnerability to flood, medium drainage density indicate areas with moderate vulnerability to flood and low drainage density indicate area with low vulnerability to flood. Figure 5 shows the drainage density map. 


\section{Soil Type}

Soil data was gotten from the Harmonised World Soil Database (HWSD) viewer. The data was pre-processed to a format that can be used for the analysis using ArcGIS. The data was digitised and then converted to a raster format. The type of soil in the basin area was Sandy Clay Loam.

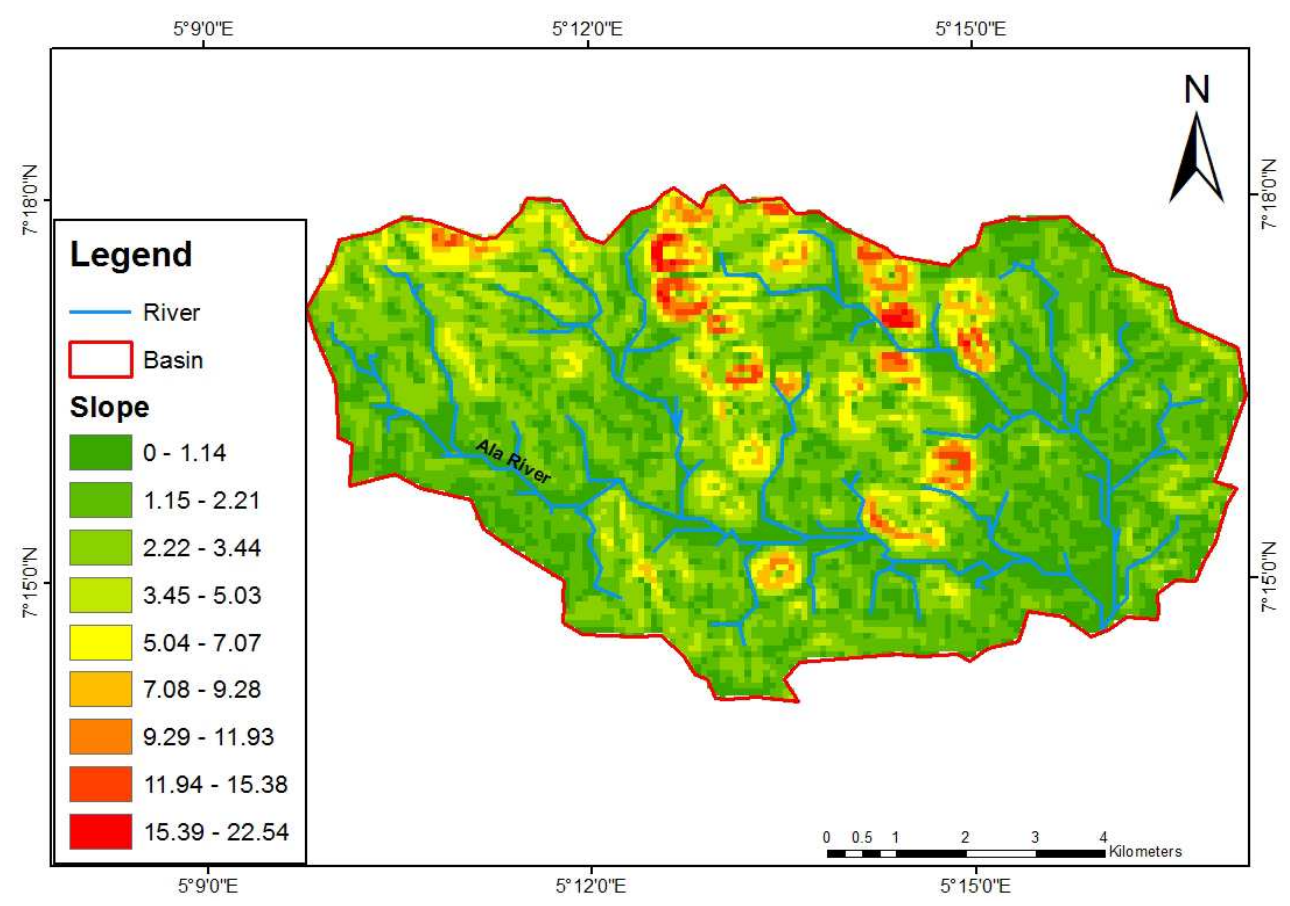

Fig. 2: Map showing slope of Ala River Basin

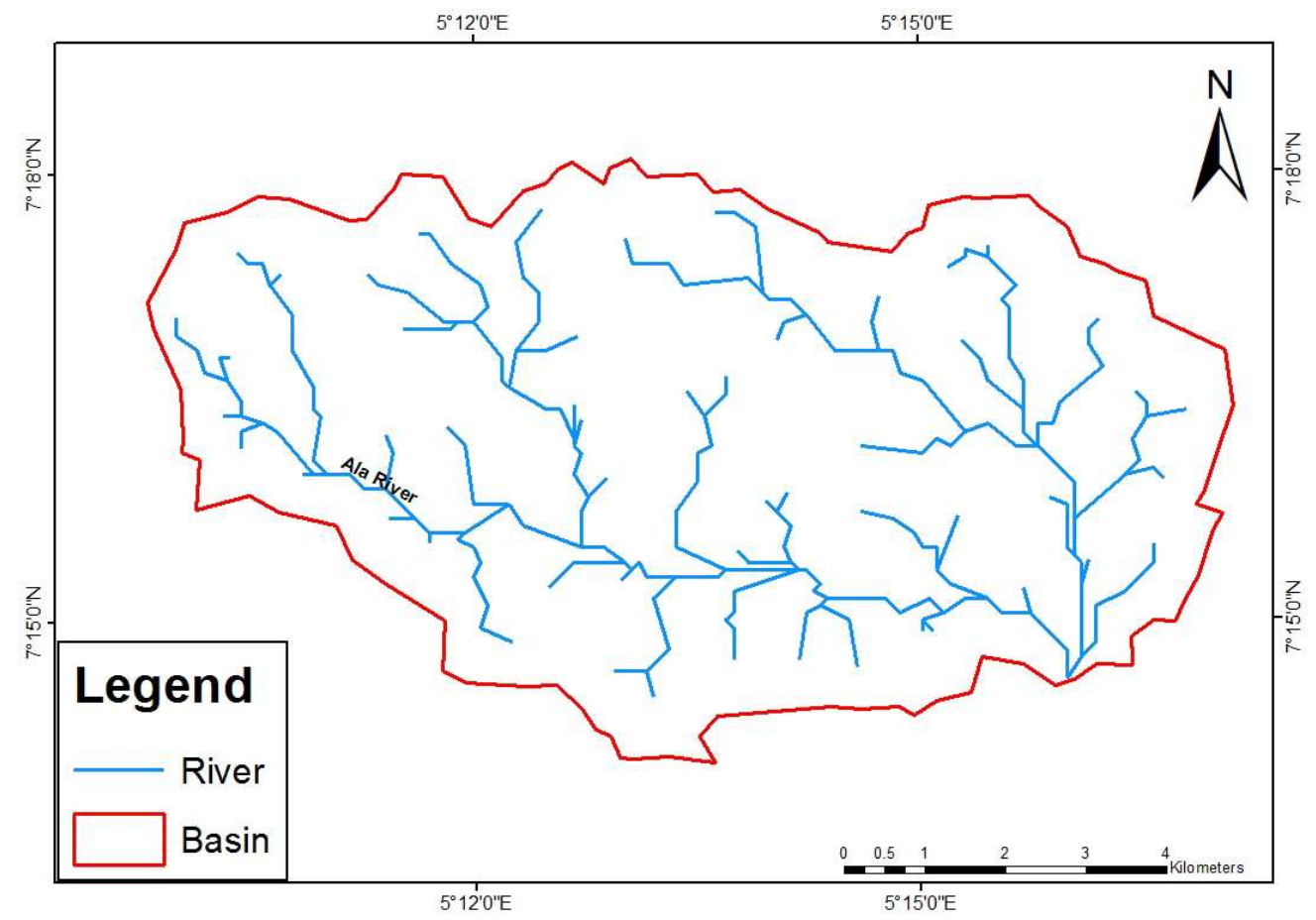

Fig. 3: Map showing drainage system in Ala River Basin 


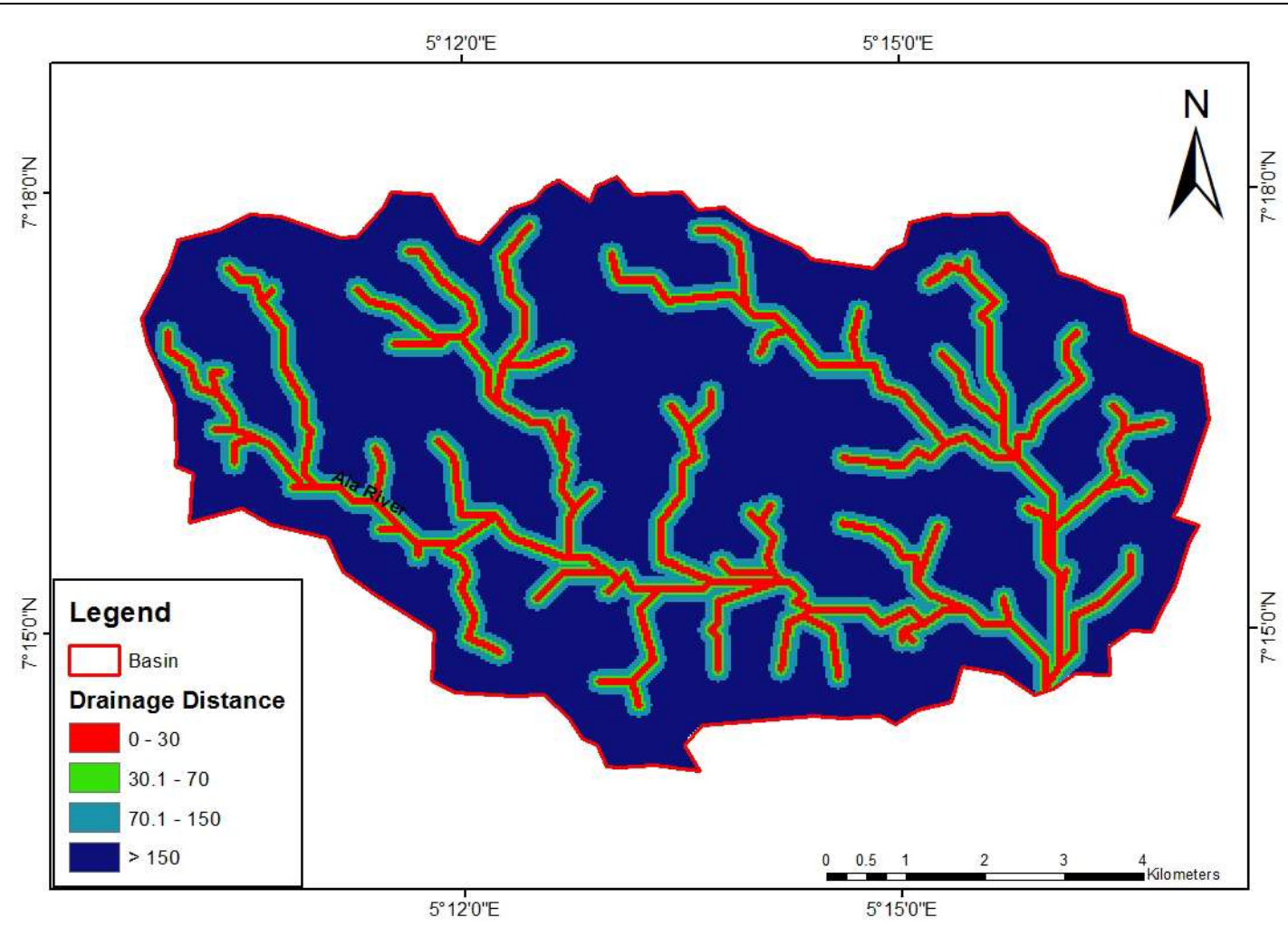

Fig. 4: Map showing distance to drainage system in Ala River Basin

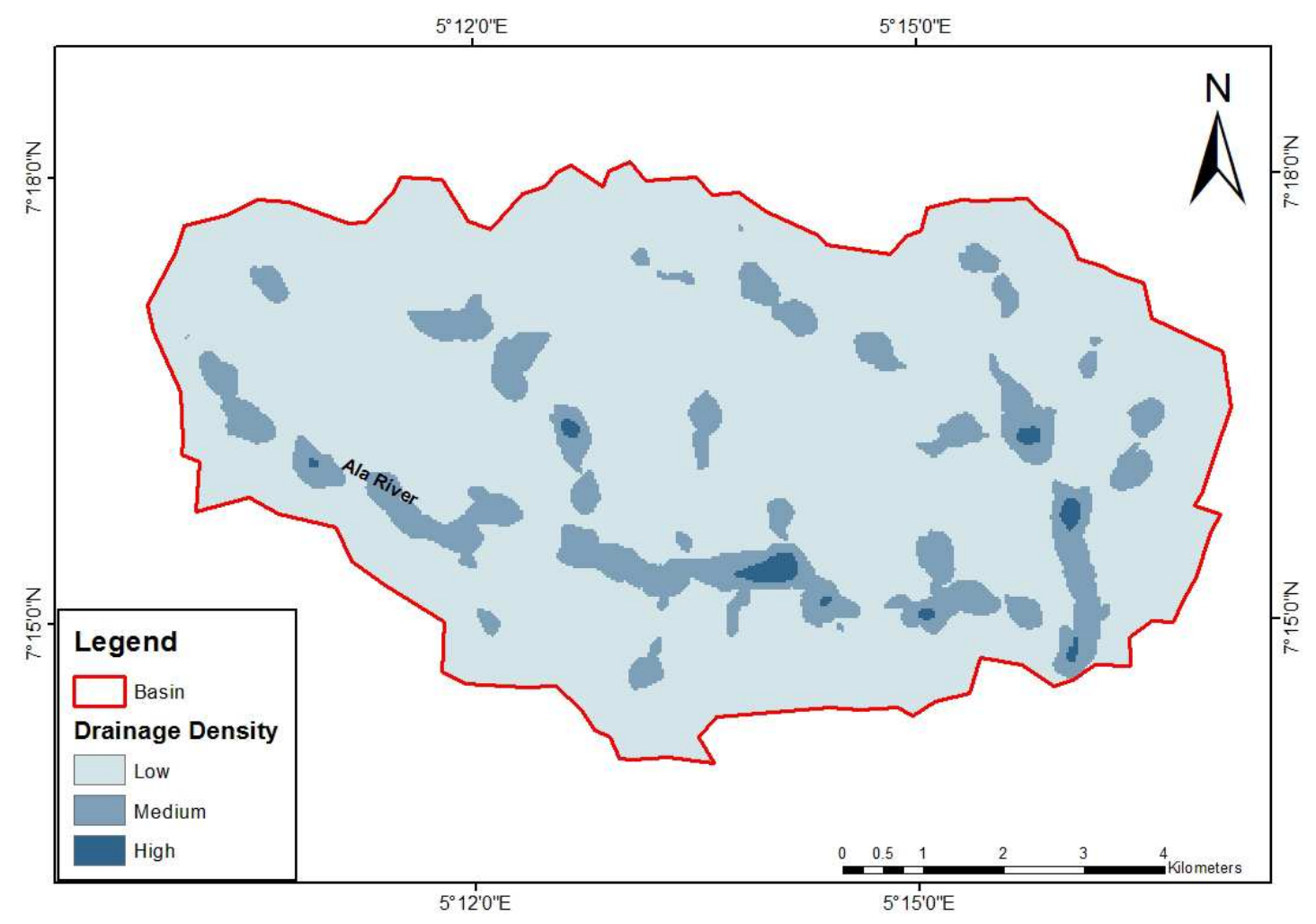

Fig. 5: Map showing drainage density in Ala River Basin 


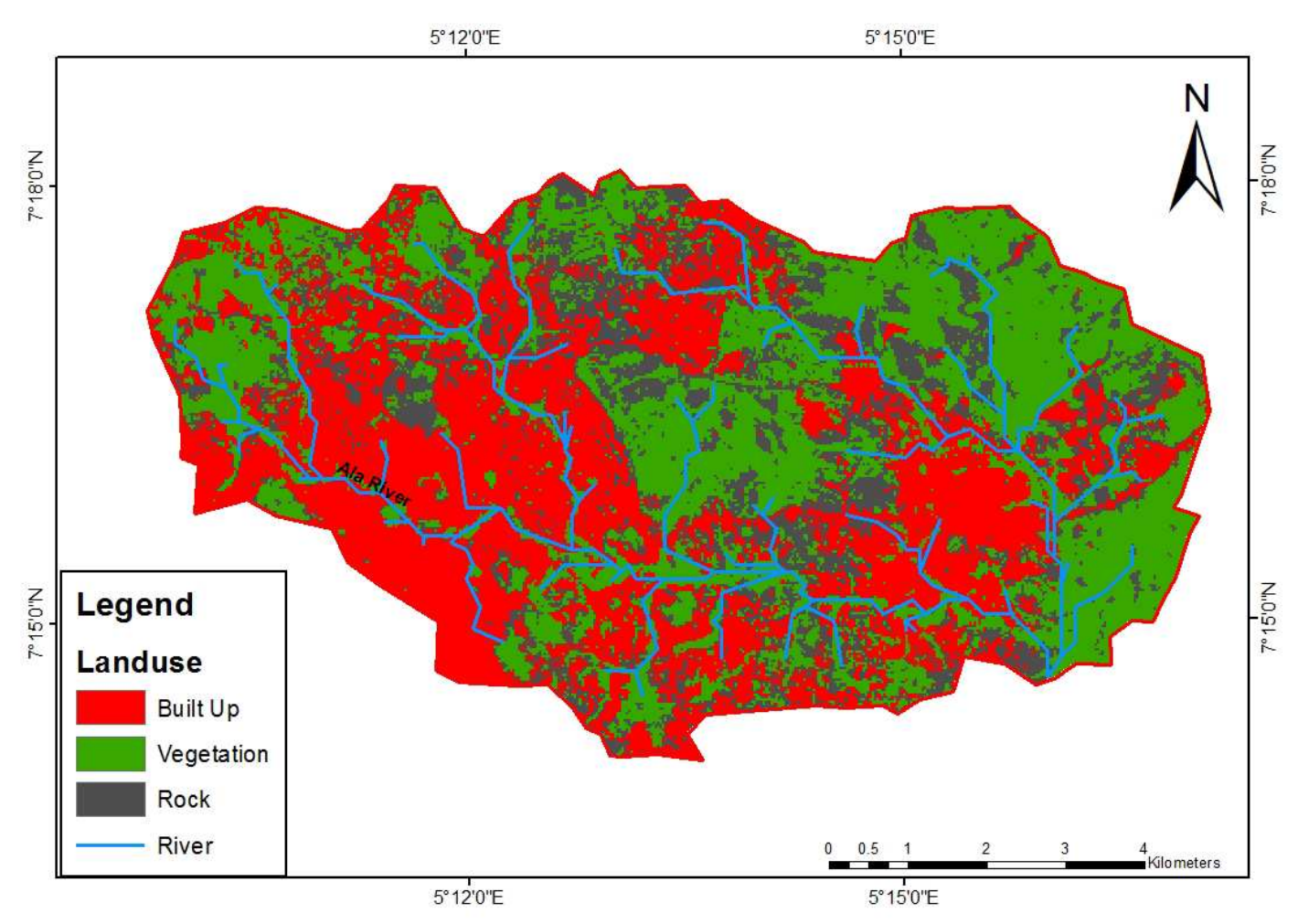

Fig. 6: Map Showing land use pattern in Ala river Basin

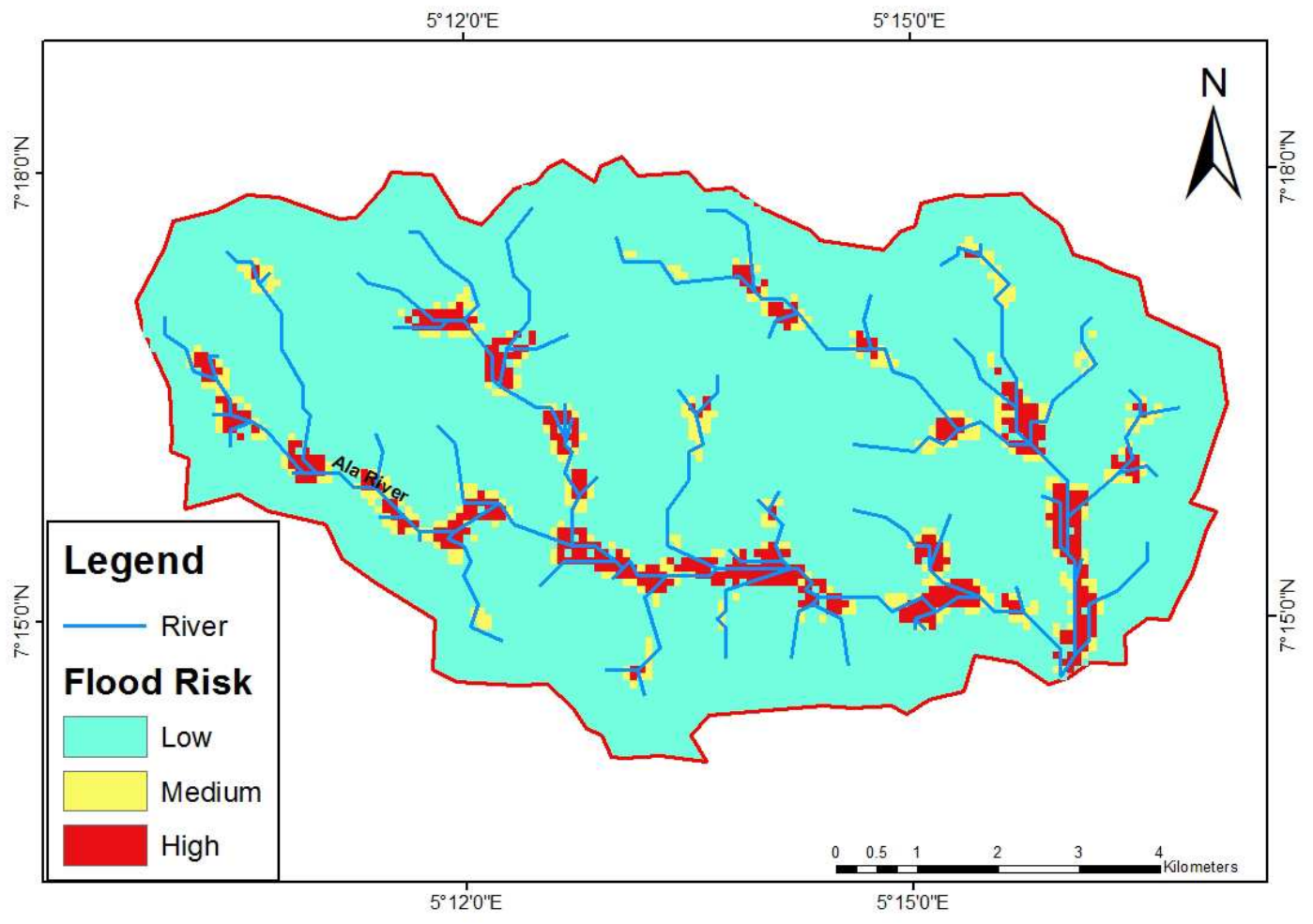

Fig. 7: Map showing flood risk in Ala River Basin 


\section{Landuse}

The landuse of the basin area was generated from raster processing of google earth imagery using supervised classification method. Four major types of land use were discovered in the area; Built Up, Vegetation, Rocks and water body. Figure 6 shows the land use types within the study area.

\section{Flood Risk Map}

The flood risk map shows area of high, medium and low vulnerability. The areas identified as highly vulnerable to flood were places where there is high drainage density which indicates locations tributaries flow into the main Ala river course. Figure 7 shows the flood risk within the study area.

\section{Conclusion}

Fuzzy logic has been proven to be a useful tool for flood risk mapping in Ala River basin area. Five criteria were used to determine the places with various flood risk levels. The criteria are distance to drainage, drainage density, slope, soil type and land use. The criteria were placed in various fuzzy membership class. The final result was then generated using the fuzzy overlay of all the criteria fuzzy membership. The places that have high risk of flooding are those areas close to the river banks and especially the areas that the tributaries empty into the main river.

\section{Recommendation}

The flood risk map generated from this study can be made available to policy makers and the government as a support for decision making when tackling the problem of flood in Ala River basin area. Fuzzy logic procedures, if embraced by the government, can be used in disaster management at all levels. The final output which would be in form of a risk map would help in all aspect of disaster management. From the process of preparedness, where the government would know what to prepare for and to what extent to prepare. Response, where the government would locate areas of high emergency and know the rate of response that would be required. Mitigation, where the government would know how avoid repitition of such occurrences. It also aid future prediction and early warning for disaster.

\section{Acknowledgement}

My appreciation goes to Dr. Mowumi Alabi for giving us a challenge of submitting a paper during the period we did her course work.

\section{Funding Information}

No funding

\section{Author's Contributions}

All authors equally contributed in this work.

\section{Ethics}

There are no etthical issues as this paper is part of a course work assignment.

\section{References}

Ajin, R.S., R.R. Krishnamurthy, M. Jayaprakash and P.G. Vinod, 2013. Flood hazard assessment of Vamanapuram River Basin, Kerala, India: An approach using Remote Sensing and GIS techniques. Adv. Applied Sci. Res., 4: 263-274.

Awosika, L.F and R. Folorunsho, 2000. Integrated monitoring of flood and information. Dissemination for Flood Early Warnings in Nigeria, Nigeria Institute for Oceanography and Maritime Research VI Lagos.

Chen, J., A.A. Hill and L.D. Urbano, 2009. A GISbased model for urban flood inundation. J. Hydrol., 373: 184-192.

DOI: $10.1016 /$ j.jhydrol.2009.04.021

Cooray, P.G., 1970. Note on the Charnockites of the Akure-Ado Ekiti area, western Nigeria. Proceedings of the Conference on African Geology, (CAG' 70), Department of Geology, U.I., pp: 45-53.

http://seunaadebowale.blogspot.com.ng/2011/04/akuresecological-problems-and_26.html

Huong, H.T.L. and A. Pathirana, 2013. Urbanization and climate change impacts on future urban flooding in Can Tho city, Vietnam. Hydrol. Earth Syst. Sci., 17: 379-394.

DOI: $10.5194 /$ hess-17-379-2013

Jones, H.A. and R.D. Hockey, 1964. The geology of part of South-Western Nigeria. Geol. Survey Bull., 31: 1-101.

Oyawoye, M.O., 1970. The basement complex of Nigeria. Proceedings of the Conference on African Geology, (CAG' 70), Department of Geology, UI, pp: 57-99.

Pedersen, A.N., P.S. Mikkelsen and K. ArnbjergNielsen, 2012. Climate change-induced impacts on urban flood risk influenced by concurrent hazards. J. Flood Risk Manage., 5: 203-214. DOI: $10.1111 / \mathrm{j} .1753-318 X .2012 .01139 . \mathrm{X}$

Rahaman, M.A., 1988. Recent Advances in the Study of the Basement Complex of Nigeria. In: Precambrian Geology of Nigeria, Geol. Surv. Nig., pp: 11-43. 
Schanze, J., 2006. Flood Risk Management- a Basic Framework. In: Flood Risk Management-Hazards, Vulnerability and Mitigation Measures, Schanze, J., E. Zeman and J. Marsalek (Eds.), Springer, pp: 149-167.

Scheuer, S. and V. Meyer, 2007. FloodCalc. Software tool for the calculation of multicriteria flood damage and risk maps.

Sowmya, K., C.M. John and N.K. Shrivasthava, 2015. Urban flood vulnerability zoning of Cochin City, southwest coast of India, using remote sensing and GIS. Nat. Hazards, 75: 1271-1286.

DOI: $10.1007 / \mathrm{s} 11069-014-1372-4$
Suleiman, Y.M, M.B. Matazu, A.A. Davids and M.C. Mozie, 2014. The application of geospatial techniques in flood risk and vulnerability mapping for disaster management at Lokoja, Kogi State, Nigeria. J. Environ. Earth Sci., 4: 54-61. 